\title{
Eletroforese de proteínas séricas de tartarugas cabeçudas (Caretta caretta) de vida livre e mantidas em cativeiro no litoral norte da Bahia
}

\author{
Thaís Torres PIRES ${ }^{2}$ \\ Gonzalo ROSTAN ${ }^{2}$ \\ Thereza Cristina Calmon de \\ BITTENCOURT ${ }^{3}$ \\ Maria Ângela Ornelas de \\ ALMEIDA $^{1}$ \\ José Eugênio GUIMARÃES'1
}

\section{Correspondência para:}

ThaísPires; thais.vet@tamar.org.br, Cx. Postal 2219 Rio Vermelho, CEP: 40223-970 Salvador-BA

Recebido para publicação: 14/09/2007 Aprovado para publicação: 30/10/2008

\author{
1 - Departamento de Patologia e Clínicas da Escola de Medicina Veterinária da \\ Universidade Federal da Bahia, Salvador-BA \\ 2 - Projeto TAMAR-ICMBio, Mata de São João-BA \\ 3 - Departamento de Produção Animal da Escola de Medicina Veterinária da \\ Universidade Federal da Bahia, Salvador-BA
}

\section{Resumo}

Este trabalho objetivou a determinação e comparação do perfil eletroforético das proteínas séricas de tartarugas cabeçudas (Caretta caretta), fêmeas, de vida livre $(\mathrm{n}=20)$ que desovam no Litoral Norte da Bahia e daquelas mantidas em cativeiro $(n=5)$ no Centro de Visitantes do Projeto Tamar-Ibama da Praia do Forte, Bahia, Brasil. Os valores obtidos para os animais de vida livre para as variáveis foram: proteína total de $3,84 \pm 0,56 \mathrm{~g} / \mathrm{dL}$, albumina $1,39 \pm 0,30 \mathrm{~g} / \mathrm{dL}$, alfa-1 e alfa-2 globulina $0,34 \pm 0,09 \mathrm{~g} / \mathrm{dL}$ e $0,42 \pm 0,22 \mathrm{~g} / \mathrm{dL}$, beta globulina $0,57 \pm 0,26 \mathrm{~g} / \mathrm{dL}$ e gama globulina $1,16 \pm 0,30 \mathrm{~g} / \mathrm{dL}$, e relação A:G de $0,58 \pm 0,16$. Para os animais cativos estes valores foram de: proteína total 4,98 $\pm 1,31 \mathrm{~g} / \mathrm{dL}$, albumina $1,64 \pm 0,55 \mathrm{~g} / \mathrm{dL}$, enquanto que para as frações alfa- 1 , alfa- 2 , beta e gama globulinas de $0,39 \pm 0,24 \mathrm{~g} / \mathrm{dL}$, $0,68 \pm 0,44 \mathrm{~g} / \mathrm{dL}, 0,68 \pm 0,13 \mathrm{~g} / \mathrm{dL}$ e $1,59 \pm 0,31 \mathrm{~g} / \mathrm{dL}$, respectivamente; e para a relação $A: G$ de $0,49 \pm 0,08$. Avaliando os resultados observaram-se diferenças estatísticas significativas $(\mathrm{p}<0,05)$ para os valores de proteína total onde os animais de cativeiro apresentaram níveis mais elevados, o que pode ser atribuído a alimentação rica em proteína oferecida, e para a gama globulina onde o grupo de vida livre obteve valores inferiores, possivelmente devido a uma imunodepressão relacionada ao estresse reprodutivo. Apesar destas diferenças o padrão eletroforético foi semelhante entre os grupos estudados.

\section{Introdução}

O litoral norte da Bahia é uma das principais áreas de desova de tartarugas marinhas no Brasil, principalmente das tartarugas cabeçudas (Caretta caretta) e tartarugas de pente (Eretmochelys imbricata) ${ }^{1}$ Outras espécies como a oliva (Lepidochelys olivacea) e verde (Chelonia mydas) também freqüentam este litoral, porém em menor número. Assim, esta área apresenta grande importância biológica para estas espécies, pois grande parte das desovas registradas na costa brasileira ocorre em praias baianas, mais especificamente na Praia do Forte no município de Mata de São João e em
Arembepe no município de Camaçari.

Sendo a tartaruga cabeçuda a espécie com maior índice de desova nas praias do continente, no Brasil ${ }^{2,3}$, ela contribui com cerca de $80 \%$ dos ninhos durante cada estação reprodutiva. Todas as espécies de tartarugas marinhas são listadas como vulneráveis ou ameaçadas de extinção pela World Conservation Union ${ }^{4}$ e o Projeto Tamar-ICMBio é responsável pela pesquisa e conservação das tartarugas marinhas no Brasil desde 1980².

Os esforços para conservar as espécies de tartarugas marinhas e os avanços na medicina veterinária por meio da realização de estudos de seus parâmetros 
fisiológicos têm crescido recentemente. ${ }^{5}$ Entretanto, ainda são escassas as informações de valores de parâmetros sangüíneos para estes animais. A avaliação do estado fisiológico de populações de espécies ameaçadas se faz necessária para o desenvolvimento apropriado de planos de manejo e conservação. ${ }^{6}$

A eletroforese de proteínas é de grande valor como método auxiliar para o diagnóstico de doenças e compreensão de alterações fisiológicas ${ }^{7,8}$, pois mudanças dramáticas nas frações protéicas são evidentes em diversas enfermidades e podem auxiliar na procura de um real diagnóstico, quando outros testes são pouco conclusivos. Esta técnica proporciona informações importantes sobre vários componentes de proteínas do soro ou plasma, os quais podem ajudar no diagnóstico diferencial em muitos casos, além de requerer pequena quantidade de amostra para o seu processamento. Ela tem se mostrado um teste diagnóstico auxiliar muito útil em mamíferos e aves, que ainda precisa ser explorado na clínica de répteis e anfíbios. Assim sendo, a eletroforese de proteínas plasmáticas pode ser utilizada como uma importante ferramenta na avaliação da saúde de tartarugas marinhas, e a obtenção de valores de referência é necessária, respeitando-se as condições ambientais, nutricionais e fatores fisiológicos que possam interferir ou contribuir para aqueles dados. ${ }^{10}$

Este trabalho teve como objetivo estabelecer e comparar o perfil eletroforético de tartarugas marinhas cabeçudas (Caretta caretta), fêmeas, clinicamente saudáveis, criadas em cativeiro e em vida livre, de maneira que posteriormente possa auxiliar na avaliação clínica desta espécie.

\section{Material e Método}

Foram analisados dois grupos distintos de tartarugas marinhas cabeçudas (Caretta caretta): animais de vida livre $(n=20)$ e em cativeiro $(n=5)$. As amostras de sangue dos animais de vida livre foram coletadas das fêmeas, durante as temporadas reprodutivas, de setembro a março de 2004/2005 e 2005/2006, após desova no Litoral Norte da Bahia, em áreas protegidas pelas bases do Projeto Tamar-ICMBio da Praia do Forte $\left(12^{\circ} 34^{\prime} \mathrm{S}, 38^{\circ} 00^{\prime} \mathrm{W}\right)$ e Arembepe $\left(12^{\circ} 45^{\prime} \mathrm{S}\right.$ $\left.38^{\circ} 10^{\prime} \mathrm{W}\right)$. Para os animais em cativeiro, foram coletadas amostras de fêmeas existentes no Projeto Tamar-ICMBio, Centro de visitantes da base de Praia do Forte - Bahia, em março de 2006. Os animais foram mensurados, e os valores médios do comprimento curvilíneo de carapaça (CCC) foram de $1,00 \mathrm{~m}( \pm 0,05)$ para os animais de vida livre e $0,97 \mathrm{~m}$ $( \pm 0,03)$ para as tartarugas mantidas em cativeiro. Todos os animais foram avaliados clinicamente, onde se avaliaram condição corporal, presença de ectoparasitas, tumores e lesões cutâneas. Foram coletadas amostras apenas dos animais considerados clinicamente saudáveis.

As amostras de sangue foram coletadas do seio cervical dorsal ${ }^{11}$, imediatamente armazenadas em tubos sem anticoagulante, e em seguida enviadas ao Laboratório de Patologia Clínica do Hospital Veterinário da Escola de Medicina Veterinária da UFBA, onde foram centrifugadas para obtenção do soro, que foi congelado a $-20^{\circ} \mathrm{C}$.

A separação eletroforética das proteínas foi realizada em gel de agarose utilizando-se kit comercial (Celm Gel). As fitas de agarose foram coradas com o Amido Black e lidas em densitômetro (CELM DS-35) com comprimento de onda de $520 \mathrm{~nm}$. A proteína sérica total foi determinada pelo método do biureto modificado através de kit comercial (Labtest), com leitura espectrofotométrica em $550 \mathrm{~nm}$.

Considerando-se o número reduzido de animais entre os grupos avaliados, utilizou-se para efeito de estudo o teste não paramétrico de Mann e Whitney ${ }^{12}$, por meio 
do programa SPSS, versão 11.0, comparando-se as médias dos grupos em questão. O nível de significância usado para o teste foi de $5 \%$.

\section{Resultados}

Para efeito de visualização dos resultados as médias, desvios padrão, valores máximo e mínimo das amostras analisadas na eletroforese encontram-se na tabela 1.

De um total de 20 amostras séricas de tartarugas de vida livre, 18 revelaram as seguintes frações protéicas: albumina, alfa-1 globulina, alfa-2 globulina, beta globulina e gama globulinas (Figura 1), enquanto que em duas amostras as frações alfa-1 e alfa-2 globulina apresentaram-se unidas, revelando apenas alfa globulina, com valores individuais de 0,36 e $0,27 \mathrm{~g} / \mathrm{dl}$.

As frações protéicas obtidas para as cinco tartarugas de cativeiro foram as mesmas da maioria dos animais de vida livre.

\section{Discussão}

As bandas protéicas observadas

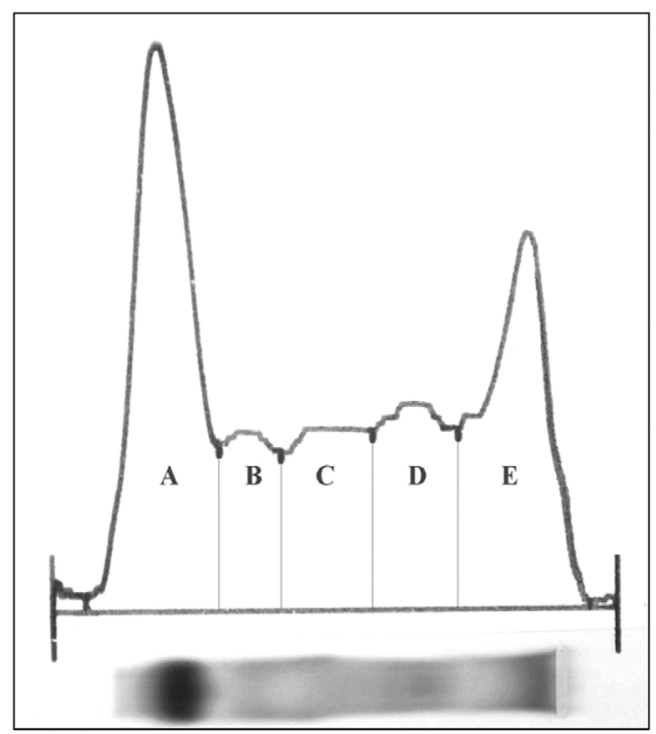

Figura 1 - Representação do eletroforetograma das proteínas séricas de tartarugas cabeçudas (Caretta caretta). A - Albumina, B - Alfa-1 globulina, C - Alfa- 2 globulina, D - Beta globulina, e E - Gama globulina

neste trabalho estão de acordo com o relato de Cray et al. ${ }^{13}$ e Work et al. ${ }^{14}$, que em estudos com tartaruga verde (Chelonia mydas) também obtiveram a separação das frações em albumina, alfa-1 globulina, alfa-2 globulina, beta globulina e gama globulinas. Entretanto, Gicking et al. ${ }^{10}$ ao

Tabela 1 - Médias, desvios-padrão, valores máximo e mínimo de proteína total, das frações albumina, alfa-1 e alfa-2 globulina, beta globulina e gama globulina, obtidas pela separação eletroforética, e relação A:G de amostras séricas de tartarugas marinhas (Caretta caretta) de vida livre $(n=20)$, de cativeiro $(n=5)$ e de vida livre e cativeiro juntas $(n=25)$. Bahia -2006

\begin{tabular}{|c|c|c|c|c|c|c|c|}
\hline & $\begin{array}{c}\text { Prot.Total } \\
(\mathbf{g} / \mathbf{d L}) \\
(\mathrm{n}=\mathbf{2 0})\end{array}$ & $\begin{array}{c}\text { Albumina } \\
(\mathbf{g} / \mathbf{d L}) \\
(\mathbf{n}=\mathbf{2 0}) \\
\end{array}$ & $\begin{array}{l}\text { Alfa-1 } \\
(\mathrm{g} / \mathrm{dL}) \\
(\mathrm{n}=18) \\
\end{array}$ & $\begin{array}{l}\text { Alfa-2 } \\
(\mathrm{g} / \mathrm{dL}) \\
(\mathrm{n}=18) \\
\end{array}$ & $\begin{array}{c}\text { Beta } \\
(\mathrm{g} / \mathrm{dL}) \\
(\mathrm{n}=\mathbf{2 0}) \\
\end{array}$ & $\begin{array}{l}\text { Gama } \\
(\mathrm{g} / \mathrm{dL}) \\
(\mathrm{n}=\mathbf{2 0}) \\
\end{array}$ & $\begin{array}{c}\mathbf{A}: \mathbf{G} \\
(\mathbf{n}=\mathbf{2 0})\end{array}$ \\
\hline \multicolumn{8}{|c|}{ Animais de vida livre } \\
\hline Média & $3,84^{*}$ & 1,39 & 0,34 & 0,42 & 0,57 & $1,16^{*}$ & 0,58 \\
\hline Desvio-padrão & 0,56 & 0,30 & 0,09 & 0,22 & 0,26 & 0,30 & 0,16 \\
\hline Valor máximo & 4,88 & 2,10 & 0,52 & 0,89 & 1,05 & 1,63 & 1,06 \\
\hline Valor mínimo & 2,42 & 0,80 & 0,17 & 0,11 & 0,20 & 0,55 & 0,40 \\
\hline \multicolumn{8}{|l|}{ Animais cativos } \\
\hline Média & $4,98 *$ & 1,64 & 0,39 & 0,68 & 0,68 & $1,59 *$ & 0,49 \\
\hline Desvio-padrão & 1,31 & 0,55 & 0,24 & 0,44 & 0,13 & 0,31 & 0,08 \\
\hline Valor máximo & 6,83 & 2,42 & 0,77 & 1,36 & 0,83 & 1,89 & 0,55 \\
\hline Valor mínimo & 3,25 & 1,12 & 0,10 & 0,24 & 0,48 & 1,09 & 0,34 \\
\hline \multicolumn{8}{|c|}{ Animais de vida livre e cativos } \\
\hline Média & 4,07 & 1,44 & 0,35 & 0,47 & 0,59 & 1,25 & 0,56 \\
\hline Desvio-padrão & 0,87 & 0,36 & 0,13 & 0,29 & 0,24 & 0,34 & 0,14 \\
\hline Valor máximo & 6,83 & 2,42 & 0,77 & 1,36 & 1,05 & 1,89 & 1,06 \\
\hline Valor mínimo & 2,42 & 0,80 & 0,10 & 0,11 & 0,20 & 0,55 & 0,34 \\
\hline
\end{tabular}

$* \mathrm{p}<0,05$ 
realizarem a eletroforese das proteínas plasmáticas de tartarugas cabeçudas (Caretta caretta) não obtiveram as frações alfa-1 e alfa-2 globulinas, separadamente, fato que também ocorreu com dois animais de vida livre desta pesquisa. Possivelmente, a técnica utilizada não possuía sensibilidade suficiente para a determinação separada destas bandas.

A determinação da proteína total sérica através do método de Biureto é considerada mais acurada e precisa do que pela refratometria ${ }^{10}$. Os valores obtidos neste estudo, de $3,84 \mathrm{~g} / \mathrm{dL}$ para as tartarugas de vida livre e $4,98 \mathrm{~g} / \mathrm{dL}$ para as cativas, foram próximos àqueles publicados para tartaruga cabeçuda, de 4,1 $\pm 1,2 \mathrm{~g} / \mathrm{dL}^{15}, 4,1 \pm 1,0 \mathrm{~g} / \mathrm{dL}^{16}, 4,4 \pm 0,75$ $\mathrm{g} / \mathrm{dL}^{10}, 4,0 \pm 0,8 \mathrm{~g} / \mathrm{dL}^{17}$ e $4,2 \pm 0,4 \mathrm{~g} /$ $\mathrm{dL}^{18}$. Foi observada diferença significativa entre os valores de proteína sérica total dos grupos estudados, onde os animais cativos apresentaram valores mais elevados $(4,98 \pm 1,31 \mathrm{~g} / \mathrm{dL})$ que os animais de vida livre $(3,84 \pm 0,57 \mathrm{~g} / \mathrm{dL})$. Embora esta diferença possa ser atribuída ao manejo nutricional, conforme cita a literatura ${ }^{19}$ para tartarugas mantidas em cativeiro, neste estudo constatou-se que o maior valor para esta variável neste grupo foi em decorrência da gama globulina.

Os valores encontrados para albumina, alfa-1 globulina, alfa-2 globulina e beta globulina (Tabela 1) não apresentaram diferença significativa entre os grupos, entretanto a fração gama globulinas, de $1,16 \mathrm{~g} / \mathrm{dL}$ para os animais de vida livre e $1,59 \mathrm{~g} / \mathrm{dL}$ para as tartarugas de cativeiro, apresentou diferença significativa $(p<0,05)$, o que pode ser atribuído a fatores fisiológicos como estresse reprodutivo e liberação hormonal, além da dieta. Ressalta-se que apesar de mais elevados os valores obtidos para o grupo de animais de cativeiro são próximos àqueles relatados pela literatura.

Os valores das frações protéicas encontrados no presente trabalho foram inferiores aos obtidos por Cray et al. ${ }^{13}$, que, em trabalho com 16 tartarugas verdes de cativeiro, apresentaram os seguintes valores: albumina $3,5 \pm 0,7 \mathrm{~g} / \mathrm{dL}$, alfa-1 globulinas $0,4 \pm 0,2 \mathrm{~g} / \mathrm{dL}$, alfa-2 globulinas $1,2 \pm 0,3 \mathrm{~g} / \mathrm{dL}$, beta globulinas $1,1 \pm 0,2$ $\mathrm{g} / \mathrm{dL}$ e gama globulinas $1,4 \pm 0,3 \mathrm{~g} / \mathrm{dL}$. Esta variação de valores pode ter ocorrido devido à diferença na metodologia da determinação da proteína total, pois estes autores utilizaram a refratometria. Ao comparar os valores encontrados neste estudo com aqueles obtidos por Gicking et al. ${ }^{10}$ para sete fêmeas adultas de tartarugas cabeçudas, pode-se observar que os valores apresentados por estes autores foram levemente inferiores para a albumina $(0,97 \pm 0,13 \mathrm{~g} / \mathrm{dL})$ e alfa globulinas $(0,49 \pm 0,05 \mathrm{~g} / \mathrm{dL})$, enquanto que para beta globulinas $(0,81 \pm 0,14 \mathrm{~g} /$ $\mathrm{dL})$ e gama globulinas $(2,1 \pm 0,64 \mathrm{~g} / \mathrm{dL})$ foram mais elevados. Vale salientar que estes autores utilizaram plasma em suas análises, onde a presença do fibrinogênio, uma das proteínas de fase aguda que compõe a fração beta globulina ${ }^{8}$, pode interferir nos resultados.

A relação A:G obtida não apresentou diferença significativa entre os dois grupos e foi maior que aquelas relatadas em estudos com tartarugas cabeçudas de $0,30 \pm 0,62$, para fêmeas adultas ${ }^{10}, 0,3 \pm 0,1^{16}$, em estudo com animais em diferentes fases de vida, e $0,4 \pm 0,08^{17}$ para juvenis desta espécie. Estas diferenças podem ser devidas a diferenças nas técnicas e pela utilização de plasma, uma vez que neste trabalho utilizou-se o soro.

\section{Conclusões}

De acordo com o protocolo experimental utilizado nesta pesquisa e com base nos resultados obtidos, pode-se concluir que o padrão eletroforético de proteínas de tartarugas Caretta caretta de vida livre e de cativeiro são semelhantes, apesar das diferenças observadas para a proteína total e gama globulina.

\section{Agradecimentos}

À CAPES e à FAPESB. 


\section{Serum protein electrophoresis of free-ranging and captive loggerhead sea turtles (Caretta caretta), from north coast of Bahia, Brazil}

\section{Abstract}

The purpose of this study was to determine and to compare the serum protein electrophoresis profile in female loggerhead sea turtles (Caretta caretta), free-ranging $(n=20)$ nesting in the north coast of Bahia and in the animals kept in captivity $(n=5)$ in the visitor center of the Projeto Tamar-Ibama, in Praia do Forte, Bahia, Brazil. The values obtained for the free-ranging turtles were: total protein $3,84 \pm 0,56 \mathrm{~g} / \mathrm{dL}$, albumin $1,39 \pm 0,30 \mathrm{~g} / \mathrm{dL}$, alfa- 1 and alfa- 2 globulin $0,34 \pm 0,09 \mathrm{~g} / \mathrm{dL}$ and $0,42 \pm 0,22 \mathrm{~g} / \mathrm{dL}$, beta globulin $0,57 \pm 0,26 \mathrm{~g} / \mathrm{dL}$, and gama globulin $1,16 \pm 0,30 \mathrm{~g} / \mathrm{dL}$, and $\mathrm{A}: \mathrm{G}$ ratio $0,58 \pm 0,16$, while for the captives ones these values were: total protein $4,98 \pm 1,31 \mathrm{~g} / \mathrm{dL}$, albumin $1,64 \pm 0,55 \mathrm{~g} / \mathrm{dL}$, alfa-1, alfa-2, beta and gama globulin $0,39 \pm 0,24 \mathrm{~g} / \mathrm{dL}, 0,68 \pm 0,44 \mathrm{~g} / \mathrm{dL}, 0,68 \pm 0,13 \mathrm{~g} / \mathrm{dL}$ and $1,59 \pm 0,31 \mathrm{~g} /$ $\mathrm{dL}$, respectively; $\mathrm{A}: \mathrm{G}$ ratio $0,49 \pm 0,08$. The total protein values were significantly higher $(p<0,05)$ for the captivity turtles; this fact may be related with the high protein feeding. Differences were also identified for the gamma globulin for the free-ranging, which presented lower values, probably due to reproductive stress and immunosuppression. Despite these considerations, the electrophoresis profile for the two loggerhead turtles groups were similar in general.

\section{Referências}

1 D'AMATO, A. F.; MARCOVALDI, A. M. Aspectos da biologia de tartarugas amerinhas (Testudenes: Chelonidae) na região de Praia do Forte Bahia. In: ENCONTRO DE ZOOLOGIA DO NORDESTE, 11. 1997, Fortaleza. Resumos ... Fortaleza, 1997. p. 54-55.

2 MARCOVALDI, M. A.; MARCOVALDI, G. G. Marine turtles of Brazil: the history and structure of projeto TAMAR-Ibama. Biological Conservation, v. 91, n.1, p. 35-41, 1999.

3 BAPTISTOTTE, C.; THOMÉ, J. C. A.; BJORNDAL, K. A. Reproductive biology and conservation status of the loggerhead sea turtle (Caretta caretta) in Espírito Santo State, Brazil. Chelonian Conservation and Biology, v. 4, n. 3, p. 523-529, 2003.

4 IUCN. 2006 IUCN red list of threatened species. Disponível em: < http://www.iucnredlist.org > . Acesso em: 12 Apr. 2007.

5 CASAL, A. B.; ORÓS, J. Morphologic and cytochemical characteristic of blood cells of juvenile loggerhead sea turtles (Caretta caretta). Research in Veterinary Science, v. 82, n. 2, p. 158-165, 2007.

6 BOLTEN, A. B.; BJORNDAL, K. A. Blood profiles for a wild population of green turtles (Chelonia mydas) in the southern Bahamas: size-espcific and sex-specific relationships. Journal of Wildlife Diseases, v. 28, n. 3, p. 407-413, 1992.
Key words:

Electrophoresis.

Protein.

Loggerhead sea turtles.
7 CRAY, C.; TATUM, L. M. Applications of protein electrophoresis in avian diagnostics. Journal of Avian Medicine and Surgery, v. 12, n. 1, p. 4-10, 1998.

8 KANEKO, J. J. Serum proteins and dysproteinemias. In: KANEKO, J. J.; HARVEY, J. W.; BRUSS, M. L. Clinical biochemistry of domestic animals. $5^{\text {th }}$ ed. San Diego: Academic Press, 1997. p. 117-138.

9 ZAIAS, J.; CRAY, C. Protein electrophoresis: a tool for the reptilian and amphibian practitioner. Journal of Herpetological Medicine and Surgery, v. 12, n. 1, p. 30-32, 2002.

10 GICKING, J. C.; FOLEY, A. M.; HARR, K. E.; RASKIN, R. E.; JACOBSON, E. Plasma protein electrophoresis of the Atlantic loggerhead sea turtles, Caretta caretta. Journal of Herpetological Medicine and Surgery, v. 14, n. 3, p. 13-18, 2004.

11 OWENS, D. W.; RUIZ G. J. New methods of obtaining blood and cerebrospinal fluid from marine turtles. Herpetologica, v. 36, n.1, p. 17-20, 1980.

12 MANN, H. B.; WHITNEY, D. R. On a test of whether one of two random variables is statistically larger than the other. Annals of Mathematical Statistics, v. 18, p. 50-60, 1947.

13 CRAY, C.; VARELLA, R.; BOSSART, G. D.; LUTZ, $P$. Altered in vitro immune responses in green turtles (Chelonia mydas) with fibropapillomatosis. Journal of Zoo and Wildlife Medicine, v. 32, n. 4, p. 436-440, 2001.

14 WORK, T. M.; RAMEYER, R. A.; BALAZS, G. H.; 
CRAY, C.; CHANG, S. P. Immune status of free-ranging green turtles with fibropapillomatosis from Hawaii. Journal of Wildlife Diseases, v. 37, n. 3, p. 574-581, 2001.

15 BOLTEN, A. B.; JACOBSON, E. R.; BJORNDAL, K. A. Effects of anticoagulant and autoanalyzer on blood biochemical values of loggerhead sea turtle (Caretta caretta). American Journal of Veterinary Research, v. 53, n. 12, p. 2224-2227, 1992.

16 BOLTEN, A. B.; BJORNDAL, K. A.; ELIAZAR, P.J.; GREGORY, L. F. Seasonal abundance, size distribution, and blood biochemical values of loggerheads (Caretta caretta) in Port Canaveral Ship Channel, Florida. Miami: NOAA, 1994. 39 p. (NOAA Technical Memorandum NMFS-SEFSC, 353).

17 KELLER, J. M.; KUCKLICK, J. R.; STAMPER, M. A.; HARMS, C. A.; MCCLELLAN-GREEN, P. D. Associations between organochlorine contaminant concentrations and clinical health parameters in loggerhead sea turtles from North Carolina, USA. Environmental Health Perspectives, v. 112, n. 10, p. 1074-1079, 2004.

18 CUBAS, P. H.; BAPTISTOTTE, C. Chelonia (tartaruga, cágado e jabuti), In: CUBAS, Z. S.; SILVA, J. C. R.; CATÃO-DIAS, J. L. Tratado de animais selvagens: medicina veterinária. São Paulo: Roca, 2006. p. 86119.

19 SWIMMER, J. Y. Biochemical responses to fibropapilloma and captivity in the green turtles. Journal of Wildlife Diseases, v. 36, n. 1, p. 102-110, 2000. 